\title{
A Primer of Ecological Statistics
}

Nicholas J. Gotelli and Aaron M. Ellison. 2004. Sinauer Associates, Inc. Publisher www.sinauer.com

pon graduation, many forest practitioners either sell or otherwise discard their statistical textbooks. Depending on their specific discipline in the field of forestry, these same individuals lament the loss of those texts. For them, A Primer of Ecological Statistics will be particularly useful.

This intermediate-level statistics book provides a refresher on the fundamentals of probability, a review for designing experiments, and a summary of data analysis techniques frequently encountered by ecologists, foresters and environmental scientists. As expected, topics such as means, standard deviations, hypothesis testing, analysis of variance, and regression are covered. In addition, managing and curating data, multivariate analysis including ordination and classification, and matrix algebra are also explored. While each of the 12 chapters covering these (and other) topics can be read independently, there is substantial cross-referencing.

The discussions of statistical techniques are largely presented in prose with a limited use of formulas and without extensive walk-throughs of examples and datasets (however some are provided). Readers will not find sample questions, problems or answers at the back of the chapter. Conversely, detailed mathematical proofs are also not provided. The authors use a casual and comfortable plain English style to describe experimental examples, statistical formulas and statistical concepts. It is written in a way that invites the reader to continue reading. In addition, there are numerous anecdotes and footnotes that cover the historical, philosophical, or mathematical nuances associated with the topic being discussed. For those short of time, the glossary provided at the back of the

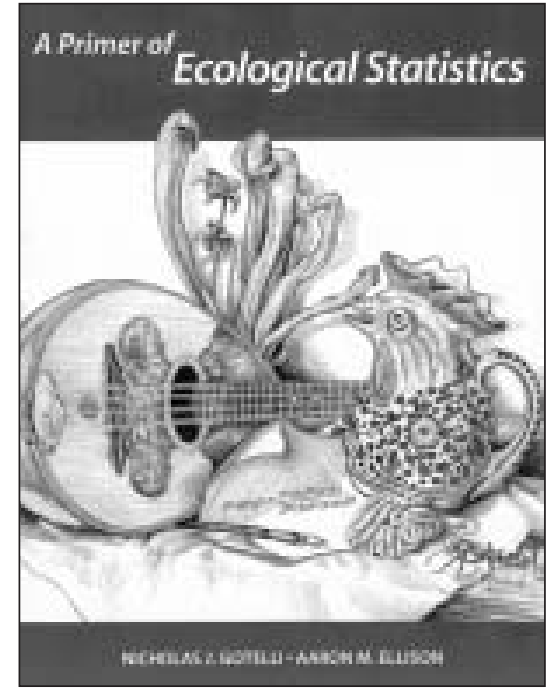

book provides a quick reminder of concepts and terms. For individuals who need to periodically plan, design, review or interpret environmental experiments and statistics, this book will be a valuable reference.

Reviewed by Michael McLaughlan Forest Ecologist Saskatchewan Environment - Forest Service

\section{The U.S. Forest Service - A History}

By Harold K. Steen. 2004. Centennial Edition. 432 p., illus., notes, index. ISBN 295-98402-3. Published in cooperation with The Forest History Society, Durham, North Carolina.

$\mathbf{T}$ his "Centennial Edition" is actually the original version published in 1976 to coincide with the centennial of forestry activities in the U.S. Department of Agriculture. A new preface has been added to mark the centennial of the U.S. Forest Service in 2005. If for no other reason, the preface makes a compelling case for an updated history of the Forest Service from a twenty-first century perspective. The first threequarters of the last century today seem benign compared to the controversies that arose in the last quarter. The $\mathrm{Na}$ tional Environmental Protection Act (1970), clean air and water, endangered species, and the National Forest Management Act (1976) had significant but yet to be objectively assessed impacts on both forest management and the forest industry. However, this is not to suggest that the book is without interest: indeed, it could aptly be sub-titled, "Personalities and Politics." The origins and shape of the Forest Service were very much the product of strong personalities, particularly of the early chiefs of the service such as Fernow, Pinchot and Greely.

The book is very much an "insider's" view as to how policies and programs were formulated. While the period covered was not without periodic controversial issues, it clearly illustrates how the chiefs and staff — the personalities - effectively prevailed over Congress
— the politics. This reviewer suggests that a yet-to-be written history of the last quarter of the twentieth century will most likely show the converse to be true.

Bernard E Fernow became chief of the Division of Forestry in 1886. He was trained in forestry in Germany and is generally accredited with introducing a more technical approach to forest management as well as economics to the profession. It was about this time that the first perceptions of an impending "timber famine" were sounded and were to persist until the late 1950s (by which time one-third of the nation's timber supply was from federal forest lands). The prevailing view in the public sector was the lack of regulation of over- 
cutting on private lands. It was generally felt that economic principles did not apply to the lumber industry - the major consumer of industrial roundwood. Additionally, the opening up of the west by the railways occasioned a steep rise in the incidence of wildfire.
Gifford Pin-

chot succeeded

Fernow as chief in 1898 until fired by President Taft in 1910. Pinchot was quite a difmuch political as Fernow was technical. He was a particularly creative manager and, faced with a meager budget and chronically short of staff, pioneered a student assistance program that attracted young men for "practical" training. However, his most significant contribution was to marshal conservation principles and give them political force by winning over President Roosevelt to his view. An interesting manifestation was that tariffs (which had been around since the time of George Washington to protect the lumber industry) were now viewed as an effective conservation measure. The forest industry naturally concurred.

The debate over regulation versus co-operation as the principal modus operandi of the Forest Service was to continue until the time of William B. Greely who became chief in 1920. After four years of lobbying Congress the Clarke-McNary Act was passed into law in 1924. Co-operation and incentives were the preferred approaches to improving conditions on private forest land. The essence of the Act is federal assistance to state and private institutions to induce voluntary action for improved forest management.

The distinguishing characteristic of the period covered is the discretionary latitude of interpretation the Forest Service had of its mandate. The key legislative statute that best exemplifies this is the Multiple Use - Sustained Yield Act of 1960 that was only one page in length. The turning point from this period of benign interpretation was probably the National Forest Management Act of 1976 that contained 15 pages of definitions, detailed restrictions on certain practices and provision for biodiversity that was utilized in litigation more frequently than even provisions in the Endangered Species Act. This in turn led to what the author has termed "judicialized decision-making."

It is more than a little ironic that for nearly a century the professional forestry community bemoaned the lack of interest of the general public. The public not only became very interested but exhibited great skepticism of the management practices of the stewards of the national forests.

Reviewed by David Boulter

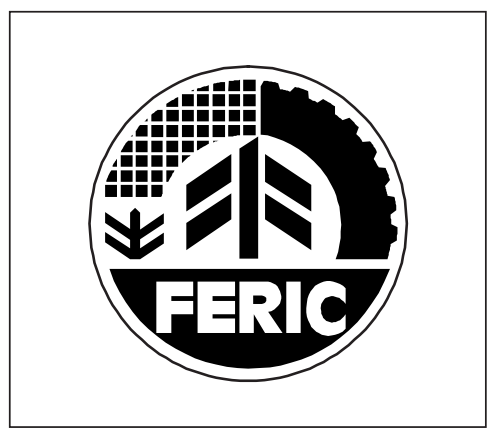

\section{Canadian Institute of Forestry/ Institut forestier du Canada}

Corporate Sustaining Members/ Membres corporatif commanditaire

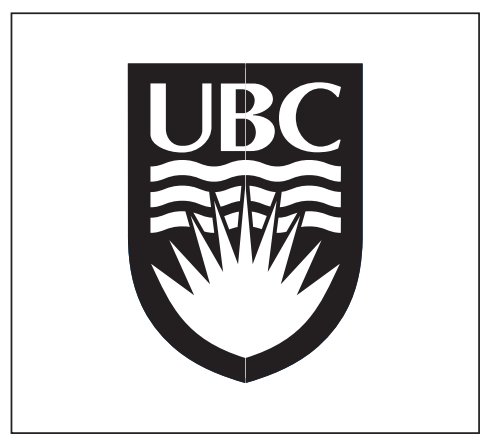

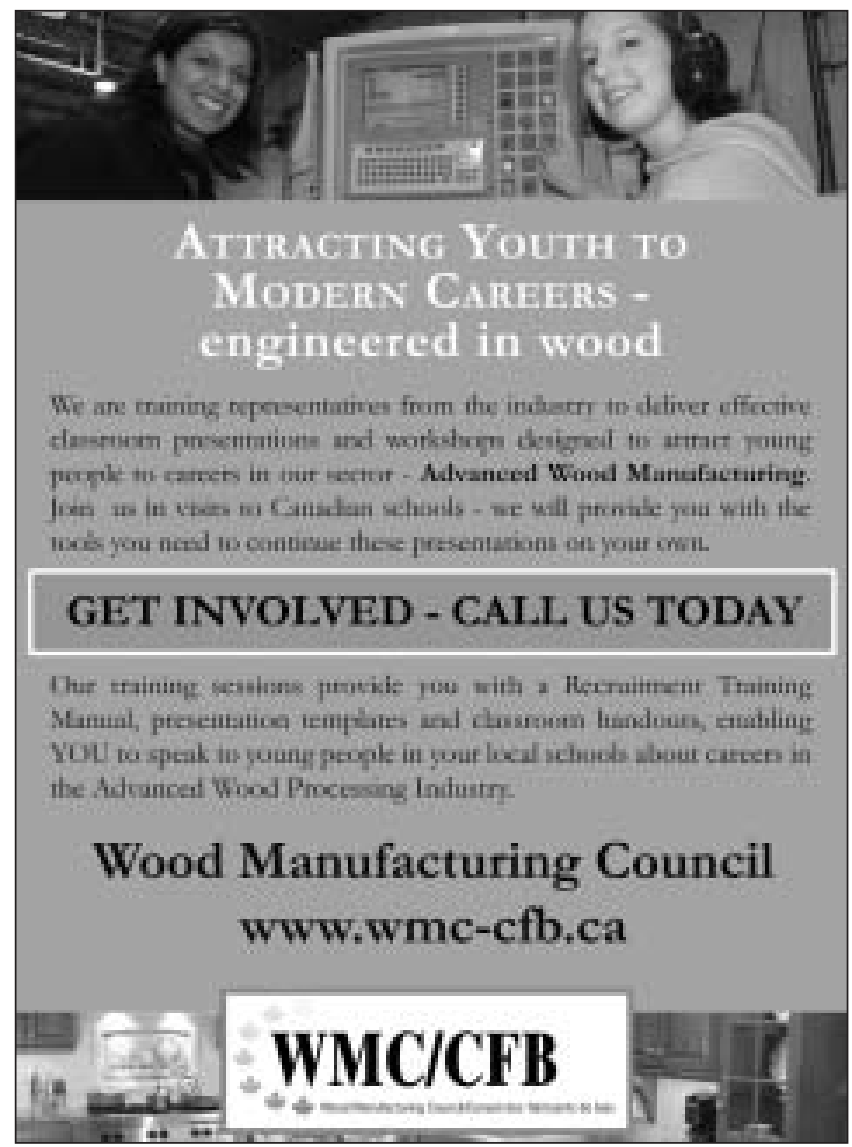




\section{Pathway to Sustainability Defining the Bounds on Forest Management}

Fedkiw J., D.W. MacCleery, V. A. Sample, 2004. Forest History Society, Durham, USA, 64 p.

$\mathrm{T}$ his booklet comprises three essays that aim at presenting the evolution of forestry in the USA. The first and main essay Sustainability and the Pathway Hypothesis is by John Fedkiw who has wide experience as a forest analyst and policy adviser with the US Forest Service. His analysis indicates that forestry first started on a very narrow track - exploitation of the forest resources - leading to a widening pathway along which the concepts of multiple use and ecosystem management have led in the direction of sustainable forest management. This process developed, he proposes, through progressive adaptation of forest management practices to the needs of society for forests and their products and services and through incorporating the results of scientific research and the experience gained over the past century in silviculture and forest ecosystem manipulation. Fedkiw insists that his "framework of understanding the Pathway Hypothesis, provides a range of feasible acceptable courses to sustainability as well as limits to those choices and their flexibility. Each course within the pathway clearly involves its own ecological, economic, and social tradeoffs to be considered in determining society's preferable course to the future."

The second essay by Douglas MacCleery, senior policy analyst for the National Forest System deals with the Historical Record of the Pathway Hypothesis. MacCleery finds historical evidence to support the concept of the widening pathway. It starts from the application to forestry of principles based on the limited science of the late $19^{\text {th }}$ century and leads towards policies that, combined with demographic and technological changes, succeeded in achieving major restoration of US forests and still continue to meet society's needs. Or, to put it another way: "American forests are, on balance, more mature than they were half a century ago. Because forest growth nationally has exceeded harvest and forest mortality for at least a half-century, average forest biomass per acre has increased by at least one-third since 1950; the only exception to this trend occurs in Pacific Coast forests, where the average biomass per acre has remained stable since 1952. In the Northeast, since 1920, due to abandonment of less productive farmland and the improving productivity of agriculture, forestland has increased by more than 40 percent or 26 millions acres." The picture is, however, less impressive in terms of species extinction. It is recognized that over the past 500 years, since Europeans started establishing themselves in America, many animal and vegetal species have disappeared or seen their intra-specific variability diminish.

The last essay is an attempt at looking forward on the pathway to sustainability. Alaric Sample, president of the Pinchot Institute for Conservation, has entitled his presentation: Sustainability and Biodiversity: The Challenge of the Future. Sample acknowledges that to date the multiple-use model has accommodated a growing array of forest uses and changing social values. But now the perceived need is to protect biological diversity in forest ecosystems as part of a global effort towards biodiversity conservation. Sample argues that the US must protect its own biodiversity hotspots while utilizing more fully those areas most suited to intensive forestry. This may require creating more nature reserves while at the same time making increased use of intensively managed plantations, and continuing to manage the majority of forests at moderate intensity for a wide variety of goods, services and values. He concludes that this practical and feasible pathway for sustainable forest management is out there waiting to be discovered.

Even if the topic is rather complex and deals with a country having a wide spectrum of experiences in private and public forestry, the authors provide a clear and well-documented picture of the evolving forestry paradigms in the US. At a time when the phrase "Sus-

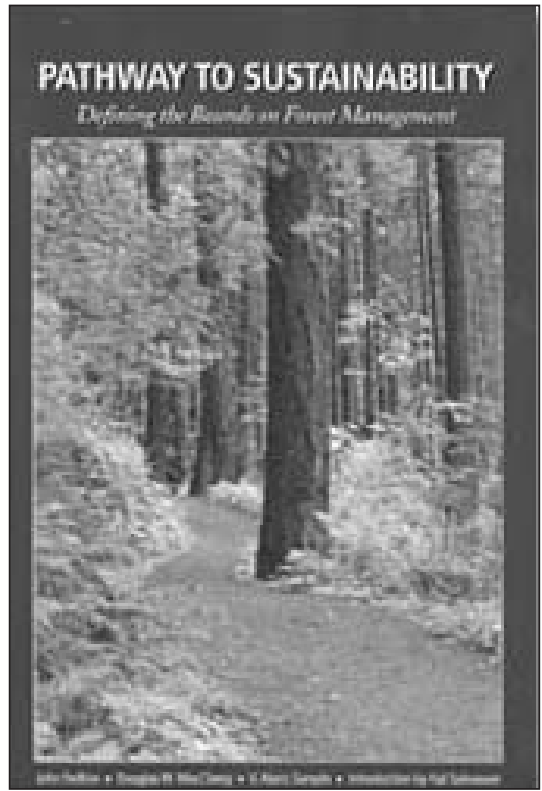

tainable Forest Management," often abridged as SFM by initiates of the debate, has become a mantra for those concerned about the future of our forests, it is interesting to witness the road (or rather the pathway), traveled by previous generations of foresters and environmentalists towards present-day forest management in the USA.

This set of essays will be of particular use to forest policy makers and of interest to all those who are curious about the evolution of forest management in a large, stable, rich and well forested country. 